\title{
Trait Emotional Intelligence and its relation to Stress during the COVID-19 Pandemic. An empirical study on professional students of Dehradun, India
}

\author{
Mamta Bhatt ${ }^{1}$, Dr Deepti Sharma ${ }^{2}$ \\ ${ }^{1}$ PhD scholar, Uttaranchal University, Dehradun, Uttarakhand \\ ${ }^{2}$ Associate Professor, Uttaranchal University, Dehradun, Uttarakhand \\ ${ }^{1}$ meenupandey17@gmail.com, ${ }^{2}$ deepti.sharma.sama@gmail.com
}

\begin{abstract}
Emotional intelligence can be defined as a behavioral perception about understanding and regulating one's emotions. Trait emotional intelligence is the psychological construct measured by self- reported questionnaires, is considered part of a typical behavior, has been well studied in relation to stress, coping, positive thinking and adaptive responses and is amenable to training and enhancement. Covid-19 and its consequent lockdown present a unique opportunity to study stress. College students are particularly vulnerable group, not only because of the fear of the disease and its social impact, but also because of the strain associated with online classes, uncertainties regarding examinations and future career prospect and an overall bleak economic scenario. This study was conducted among college students pursuing professional courses in Dehradun, India, with a valid self-reported measure of EI, a global scale of perceived stress, and a self-made questionnaire about Covid-19 related stress, with the aim of assessing their emotional intelligence and to determine its correlation with stress. One hundred and eleven students were surveyed through an online questionnaire. Emotional intelligence had significant correlation with Covid-19 related stress, but not with perceived stress. Assessment of trait EI can identify students at risk of developing high stress.
\end{abstract}

Index Terms-Emotional Intelligence, Trait EI, Stress, Covid 19, College Students

\section{INTRODUCTION}

$\mathrm{E}$ MOTIONS and stress, as a basic human trait, are as old as the history of human civilization itself. The field of emotional intelligence (EI) has seen rapid advancements in the last three decades, despite it being a relatively new subject area. The various theories, models and measuring tools are a testimony to the rising interest in this field. A lot of occupational, academic, personal and professional traits, qualities and attributes have been studied in relation to EI and their correlation with each other have been explored ${ }^{1,2}$. As expected, because of so many diverging views, there is also growing debate about the true meaning, and definition of the term as well as the correct tool to measure it. Since the landmark studies of Mayer and Salovey in early $90 \mathrm{~s}^{3}$, there have been numerous attempts by various scholars to define and describe EI in their own ways. In simple terms, Emotional Intelligence can be defined either as self- perception about one's own emotions or an ability to control negative emotions and focus on positive emotions.

Theories of Emotional Intelligence have evolved into three diverging models - Mayer and Salovey's 'ability' model, Petrides and Furnham's 'trait' model and Goleman's and BarOn's 'mixed' models. 1) According to Mayer and Salovey, emotional intelligence is the ability to perceive emotions, to access and generate emotions so as to assist thought, to understand emotions and emotional knowledge, and to reflectively regulate emotions so as to promote emotional and intellectual growth ${ }^{4}$. 2)The Goleman model holds that emotional intelligence is the capacity for recognizing our own feelings and those of others, for motivating ourselves, and for managing emotions effectively in ourselves and others ${ }^{5,6} .3$ ) Bar-On's emotional social intelligence model defines EI as those noncognitive capabilities and skills that affect one's ability to deal with social and environmental demands and pressures successfully $^{7}$. 4) The trait model defines EI is as a constellation of self - perceptions located at the lower levels of personality hierarchies $^{8}$. Mayer and Salovey argue that the ability to learn EI skills arises out of an inborn form of intelligence, and similar to IQ, EI predicts one's ability to learn emotional skills. Goleman and Bar-On believe that EI is a set of skills and competencies that can be learnt and enhanced.

Two distinct forms, ability EI and trait EI have been identified, as noted by Petrides and Furnham, and the distinction is made on the basis of measurement tool used ${ }^{9}$. According to them, measures of ability EI correlate with an individual's theoretical understanding of emotions and emotional functioning, and measures of trait EI correlate with typical behaviors in emotional situations as well as self-rated abilities ${ }^{9}$. Thus, all EI measures that are based on self-report items are called 'trait EI measures and all measures that are based on maximum performance items are called 'ability EI measures'9. These two aspects of EI are thought to be conceptually distinct ${ }^{10}$. Generally, trait EI has been reported to have stronger relation to adaptive outcomes than ability EI ${ }^{11}$. Trait EI has been shown to reduce stress reactivity in cognitive or psychosocial stress tasks in studies about self-efficacy, self-esteem and happiness $^{12}$. Another major difference between the two is the notion that while ability EI is somewhat fixed, trait EI can be improved with training. Several studies and meta-analyses have looked into this aspect of trait EI and reported improvement, 
through various training programs, in academic performance of students, and organizational performance of managers and leaders, among others ${ }^{13,14,15}$.

\section{A. Measuring tools of EI}

MSCEIT - by Mayer, Salovey, Caruso ${ }^{16}$, based on their ability model of EI, is a test of maximum performance, and is similar to IQ tests. Bar-On's Emotional Quotient inventory (EQ-I), is based on his Emotional Social Intelligence model $^{7}$, and Goleman along with Boyatzis ${ }^{17}$ developed his Emotional Competency Inventory (ECI) based on his emotional competency model. Schutte et al ${ }^{18}$ developed a self- reported test (SSEIT) based on the ability model of Mayer and Salovey. Petrides et $\mathrm{al}^{19}$, based on their Trait EI model have developed TEIQue - long and short forms. All of these tests have been extensively used and validated in different countries and population samples. Most of these are long and time consuming and not freely available with the notable exception of SSEIT. There are several advantages of using this test. First, it is freely available, unlike most other measures which are owned and run by large corporates and have to be purchased for either research or commercial use (except TEIQue-SF in a limited format). Second, it is very short and concise and takes much less time as compared to other tests. Third, it is one of the few tests, which has been used in a large and reputed meta-analysis, correlating EI with a variety of health indices. Fourth, it can be used both as a global measure of EI or a multi-dimensional scale measuring sub-sets of $\mathrm{EI}^{20}$.

This scale measures 4 components of emotional intelligence based on the 4-branch model of Mayer and Salovey, namely the appraisal, expression, and regulation of emotions of oneself and others and the utilization of emotion in problem-solving. It uses a 5-point Likert scale ranging from 1 (strongly-disagree) to 5 (strongly-agree) and comprises of 33 questions. Although some later researchers have argued for using these components as a four -factor analysis of this tool ${ }^{9}$, Schutte et al and others have advocated use of the composite scale as single factor for scoring $\mathrm{EI}^{20}$.

\section{B. Emotional Intelligence and Gender}

It is generally believed that women fare better than men in all aspects of emotions, and a large body of literature suggests the notion that women score better than men in all EI measures and domains ${ }^{21,22,23,24}$. In a review by Malouff et al describing studies employing SSEIT, it was found that although there was gender difference in EI, not all studies reported a statistically significant difference ${ }^{20}$. In a study by Petrides et $\mathrm{al}^{25}$ on trait EI, females scored higher than males on the social skills factor, but not on composite scores. Another study has shown that, it is the other demographic variable, age, rather than gender, which accounts for a larger effect on EI than gender ${ }^{26}$. Studies by several other researchers do not support the notion of women having higher EI than $\operatorname{men}^{27,28,29}$. Similar conflicting results have been reported in Indian studies. Pooja et $\mathrm{al}^{30}$, in their study on Indian professionals, found that female employees have higher EI score than males as measured by Trait EI scale. A study from Tamil Nadu, India among medical graduates, reported higher EI in females ${ }^{31}$, but another more recent study from the same state did not report any gender difference ${ }^{32}$. A study from Delhi, India, reported higher EI in females among $10^{\text {th }}$ graders ${ }^{33}$ but some of the studies from other Asian countries among college students came to the conclusion that there was no gender difference in $\mathrm{EI}^{34,35}$. In another Indian study by Shanwal et al, girls fared better than boys, though the difference was more divided on the basis of urban and rural population, and not by gender and rural boys had the highest scores on $\mathrm{EI}^{36}$. Finally, a study from South India reported a higher mean scores of EI in males than females $^{37}$. The above discussion suggests that the topic of gender difference in EI is still open to debate and definitely requires larger studies and meta-analysis to settle this point.

\section{Emotional intelligence and Stress}

Lazarus and Folkman have argued that stress results from an interaction between the individual and the environment and it depends on the coping mechanism in response to the stressful situation ${ }^{38}$. The impact of EI on stress, and coping mechanisms has been well studied. Emotional intelligence has been significantly associated with healthy functioning, distress and post- traumatic stress ${ }^{39}$. People with high EI accomplish more positive outcomes, like psychological wellbeing, higher educational qualification, and career growth. ${ }^{2}$. Some of the recent research in the field of EI is directed towards finding individual differences that influence stress responding ${ }^{40}$. Higher levels of trait EI are associated with lower levels of perceived or occupational stress $^{41}$. EI has been proposed to work as a buffer mechanism for stress and lead to positive outcomes ${ }^{42}$.

Due to the complexity of stress pathway, there are many different ways to induce stress experimentally, like reading self-evaluative statements ${ }^{43}$, showing emotive video $\operatorname{clips}^{44}$ or asking participants to deliver an impromptu speech ${ }^{45}$. Besides these 'laboratory experiments', some methods use natural stress inducers, such as an examination, or a competition ${ }^{46}$. The specific emotions and physiological outcomes that arise in a stressful situation are quite unpredictable and depend on many different factors ${ }^{47}$. For this reason, making uniform conclusions from studies that have induced stress differently is really difficult.

\section{Stress during Covid-19}

Covid -19 and its consequent nation-wide lockdown present a unique opportunity to study stress. As a uniform global phenomenon, it provides a uniform external stimulus for generation of stress, and people with different demographic, socioeconomic, educational, or vocational background are likely to have felt certain amount of stress due to the pandemic and related problems of various restrictions and economic slowdown as well as worry regarding the actual threat of the infection.

Word Health Organization declared coronavirus disease 2019 (COVID-19) as pandemic on 11 March 2020. The gov- 
ernment of India, declared a nationwide lockdown on 24th March 2020. To different extent, the lockdown has affected all sectors of the country including the education sector, which till the writing of this manuscript, remains the only sector which has not been opened fully. The closure of schools, colleges, and universities has disrupted academic activities at various levels, including examinations, admissions and placements. Apart from the changes in the mode of teaching and learning, other restrictions for preventing disease spread, uncertainties about their examinations, admissions to higher courses, placements, and jobs may contribute to enhance the stress faced by the students.

Since the onset of coronavirus pandemic, several studies have been published looking at various emotions, and stress among students, parents, and other professionals ${ }^{48,49,50,51}$, although only a few of them specifically studied the relationship of EI with stress and coping. A study from Australia reported that EI played an important part in positive coping strategies ${ }^{52}$. Another study from Poland concluded that trait emotional intelligence can predict the negative feelings of fear, sadness and anxiety associated with the pandemic. ${ }^{53}$. Some researchers have also used this opportunity to study stress with specific Covid-19 stress scales among different populations. While a study from Columbia has simply altered the perceived stress scale to add Covid-19 term in its questionnaire ${ }^{54}$, another one from Canada is a more comprehensive scale dealing with different aspects of the pandemic, but more closely related to the risk of getting infected or the health problems and the failure of preventive measures ${ }^{55}$.

Keeping this background in mind, there is clearly need for more focused studies looking at correlation of EI with this specific stress situation and to identify those susceptible individuals who can be benefitted from more targeted mentoring and counseling. As the authors plan to undertake a bigger study on emotional intelligence, a pilot study on students was undertaken. In this study, an attempt was made to understand the level of emotional intelligence of college students, the stress faced by them and to see if there exits any correlation between the two. We attempted to not only measure EI with an internationally valid tool, but also developed a short and concise Covid stress scale to assess the stress caused by the effects of lockdown, mainly affecting students.

\section{AIMS AND OBJECTIVES}

The present study was undertaken with an aim to assess the emotional intelligence of college students studying in professional institutes of Dehradun, Uttarakhand (India), and its correlation with Stress. The main objectives were defined as-

1. To determine EI by Schutte Self-reported Emotional Intelligence Scale of college going students of Dehradun pursuing professional courses.
2. To determine general stress by Perceived Stress Scale and specific Covid induced stress by a self - made stress questionnaire.

3. To determine correlation between EI and Stress.

Evaluating gender difference in EI was kept as a secondary objective, keeping in mind the small sample requirement.

\section{MATERIAL AND METHODS}

The sample population was college students of both genders, pursuing professional courses in various professional institutes of Dehradun, Uttarakhand, India. As it is a pilot study, a minimum sample of 100 was considered optimum. An online survey with three different questionnaires was planned. Because of the restrictions placed by the lockdown, participants were contacted through various social media platforms and contacts. All data were collected confidentially after informing the participants in detail about the study. The initial part of the survey included the demographic parameters. Following standard tools were used for the study. 1) For measuring Emotional Intelligence, Schutte Self-report Emotional Intelligence Test (SSEIT) was used. It consists of 33 questions regarding self- perception of emotions. Participants respond to items on a 5-point Likert-type scale ranging from 1 (stronglydisagree) to 5 (strongly-agree). For calculating EI, sum of all scores (as numbered in the options) is calculated. 2) For measuring stress, Perceived Global Scale for Stress (PSS) comprising 14 questions was used ${ }^{56}$. Each item is rated on a 5 points scale from 1 (never) to 5 (very often). As with EI scale, here also, sum of all options gives the total stress scale. Finally, a self-made stress questionnaire specifically dealing with stress related to Covid -19 was used with 8 questions with options similar to PSS (given in supplement). Following statistical analyses were done. 1) For internal reliability of scales, Cronbach alpha was calculated for all three questionnaires. Validity of Covid stress scale was tested with Pearson coefficient. 2) For comparing EI between genders, t-test for significance was employed. 3) For correlation between EI and Stress, Pearson's Correlation coefficient was used. SPSS (IBM Inc) version 23 was used for statistical analysis.

\section{RESULTS}

\section{A. Demographics}

A total of one hundred and eleven college students fulfilled the questionnaires completely and were subjected to analysis. Sixty-eight (61\%) were females. Average age was 20.7 years. Maximum responders were from management courses. The majority of students belong to Uttarakhand and Uttar Pradesh. About three-fourths of participants were aware about the concept of EI. Table 1 summarizes the demographic details.

\section{B. Validity and Reliability}

Cronbach alpha for each questionnaire dealing with emotional intelligence, Perceived Global Stress and Covid related stress, respectively, was $0.897,0.817$, and 0.798 , which showed good internal reliability of all three as a value greater 
TABLE- 1- DEMOGRAPHIC DETAILS OF STUDY PARTICIPANTS

\begin{tabular}{|l|l|l|}
\hline Age & & \\
\hline & Mean & 20.7 \\
\hline & Range & $18-26$ \\
\hline & SD & 1.41 \\
\hline Gender & & \\
\hline & Females & $68(61.2 \%)$ \\
\hline Native State & Males & $43(38.8 \%)$ \\
\hline & & \\
\hline & Uttarakhand & $42(37.8 \%)$ \\
\hline & Uttar Pradesh & $24(21.6 \%)$ \\
\hline & Delhi & $7(6.3 \%)$ \\
\hline $\begin{array}{l}\text { Course } \\
\text { pursuing }\end{array}$ & Others & $38(34.3 \%)$ \\
\hline & & \\
\hline & BBA & $47(42.3 \%)$ \\
\hline & MBA & $29(26.1 \%)$ \\
\hline & Bsc/Btech & $15(13.5 \%)$ \\
\hline & Msc & $8(7.2 \%)$ \\
\hline & Others & $12(10.9 \%)$ \\
\hline & &
\end{tabular}

than 0.7 is considered adequate and above 0.8 is suggestive of good reliability (Table- 2). Testing with Pearson coefficient confirmed the validity of the Covid scale.

\section{Emotional intelligence}

The mean value for EI, for the total sample population was 130 , with SD of 16.89. This suggests an overall high to high normal level of EI of the study group. The mean score across many large samples has been reported about 124 , with a standard deviation of about 13. Mean scores below 111 or above 137 are considered unusually low or high (Malouff et al 2009). In this respect, our sample population corresponds well with previous studies with SSEIT.

TABLE 2. CRONBACH ALPHA VALUES FOR ALL THREE SCALES

\begin{tabular}{|l|l|}
\hline Scale & Cronbach alpha \\
\hline Emotional Intelligence & 0.897 \\
\hline Perceived Global Stress & 0.817 \\
\hline Covid related stress & 0.798 \\
\hline
\end{tabular}

There was a significant difference between EI scores of male and female students, with values of 128.9 for males $(\mathrm{SD}=20.23)$, and 130.9 for females $(\mathrm{SD}=14.51)$. ( $\mathrm{p}$ $<0.05$ ) ( table 3 and table 4 ). This result is comparable to previous studies, both from India and abroad, which have shown a higher emotional intelligence among females than males, although as can be seen, the actual difference in mean EI among the genders is quite small.
Table 3. EI scores of female and male students

\begin{tabular}{|l|c|r|r|c|}
\hline & $\mathrm{N}$ & $\begin{array}{c}\text { Mea } \\
\mathrm{n}\end{array}$ & $\begin{array}{c}\text { Std. } \\
\text { Deviati } \\
\text { on }\end{array}$ & $\begin{array}{c}\text { Std. } \\
\text { Error } \\
\text { Mean }\end{array}$ \\
\hline $\begin{array}{l}\text { Fema } \\
\text { les }\end{array}$ & 68 & $\begin{array}{c}130 . \\
9118\end{array}$ & $\begin{array}{r}14.5137 \\
5\end{array}$ & 1.76005 \\
\hline $\begin{array}{l}\text { Male } \\
\mathrm{s}\end{array}$ & 43 & $\begin{array}{c}128 . \\
9070\end{array}$ & $\begin{array}{r}20.2317 \\
7\end{array}$ & 3.08532 \\
\hline
\end{tabular}

\section{Stress}

The mean value for perceived stress was 31.1 with SD of 8.99, which suggests moderate degree of stress. The mean value for the Covid stress scale was 27.8 with SD of 6.36 . As expected, this scale yielded a very high level of stress among the study participants, with three of the participants scoring the maximum possible score of 38 .

Table 5 summarizes the values of the three scales.

\section{E. Correlation between trait EI and Stress}

Correlation analysis using Pearson's correlation coefficient revealed significant negative correlation between EI and Covid stress scale. There was weak negative correlation observed between EI and perceived stress, but it was not statistically significant (table 6). For correlation analysis, global scale of EI was used and subscale calculation of four individual components was not done. As role of gender was not a primary objective of the study, correlation of stress scale with male and female groups was not performed separately.

Table 6 summarizes the correlation coefficients between EI and stress scales.

\section{DISCUSSION}

To the best of our knowledge, this is the first study from the state of Uttarakhand, India, assessing the emotional intelligence and its correlation with stress during the Covid -19 pandemic and consequent lockdown. This pilot study was undertaken in a small sample of college going students studying in various professional colleges of Dehradun, which is known as an education hub in Northern India, and attracts students from different parts of the country. As the authors plan to undertake a bigger study about emotional intelligence among professionals in education sector, this pilot study was conducted for validating the questionnaires, along with the study of stress caused by the present situation. Emotional intelligence and stress have been well studied topics, both among students and working professionals. However very few Indian studies have actually used internationally valid tools for measuring EI. The coronavirus pandemic and nationwide lockdown provide a unique opportunity to study the stress and the correlation of EI with stress.

The results of the study provide some interesting points to consider. First, the overall level of EI in this study was relatively high, as measured by the SSEIT tool. This is an interna- 
TABLE 4. T-TEST AND P-VALUES FOR MEAN EI IN FEMALES AND MALES

\begin{tabular}{|c|c|c|c|c|c|c|}
\hline & \multicolumn{6}{|c|}{ Test Value $=0$} \\
\hline & \multirow[b]{2}{*}{$\mathrm{t}$} & \multirow[b]{2}{*}{ Df } & \multirow[b]{2}{*}{ Sig. (2-tailed) } & \multirow{2}{*}{$\begin{array}{c}\text { Mean } \\
\text { Difference }\end{array}$} & \multicolumn{2}{|c|}{$\begin{array}{l}\text { 95\% Confidence Interval of the } \\
\text { Difference }\end{array}$} \\
\hline & & & & & Lower & Upper \\
\hline Females & 74.380 & 67 & .000 & 130.91176 & 127.3987 & 134.4248 \\
\hline Males & 41.781 & 42 & .000 & 128.90698 & 122.6806 & 135.1334 \\
\hline
\end{tabular}

Note: P value $<0.05$

tionally valid tool to measure trait EI and has been used in previous studies among students. In several large population surveys, the mean EI score is around 124. In our study the mean EI score was 130.1, which suggests that college students pursuing professional courses have highnormal emotional intelligence. In a comprehensive review studying EI with SSEIT ${ }^{20}$, mean EI scores among different student groups in different countries have been reported to vary from 117 to 133 . Our result is fairly comparable to these studies. Second, there was a slight but significant difference in EI between male and female students. This finding is in accordance with the generally ac-

Table 5.Trait EI, Perceived StRess AND Covid StRESS SCALE VALUES ( MEAN, SD)

\begin{tabular}{|l|l|l|}
\hline $\begin{array}{l}\text { Trait Emotional } \\
\text { Intelligence }\end{array}$ & Mean & 130.1 \\
\hline & Range & $52-165$ \\
\hline & SD & 16.89 \\
\hline & Females & 130.9 \\
\hline & Males & 128.9 \\
\hline $\begin{array}{l}\text { Perceived Stress } \\
\text { (maximum possible 56) }\end{array}$ & Mean & 31.1 \\
\hline & Range & $4-50$ \\
\hline & SD & 8.99 \\
\hline & & \\
\hline $\begin{array}{l}\text { Covid Stress ( maximum } \\
\text { possible 38) }\end{array}$ & Mean & 27.8 \\
\hline & Range & $6-38$ \\
\hline & SD & 6.36 \\
\hline & &
\end{tabular}

cepted wisdom that women have better emotional intelligence than men. Several studies, including the one by Schutte et al themselves for validation of their tool came to the conclusion that women score better than men in almost all EI tools and domains ${ }^{21,22,23,24}$. However, some of the relatively recent studies have shown that the gender difference is not uniform and EI scores are equal for both the genders. Larger studies are definitely needed to clarify this issue.

The correlation analysis also showed an interesting aspect. Contrary to the available evidence and popular belief, there was no significant correlation between trait EI and general stress as measured by Perceived Stress Scale. This may be because of three reasons. First, as the sample size is small, the negative correlation may not have reached the level of significance. Although a minimum sample size of 100 is usually considered adequate for such pilot studies and for validation of questionnaire, this may not be adequate for correlation analysis. Second the EI scores of students skewed in the high normal range and very few students had low scores. This unequal distribution may also lead to inadequate correlation analysis. Finally, although Perceived Stress Scale is a validated tool for measuring stress, it may not have captured the accurate psychosocial and mental distress induced by Covid 19 pandemic. This assumption was also the reason for designing a short specific questionnaire related to specific issues about health, studies, career and economy arising out of this pandemic and lockdown. As expected, this scale produced very high scores of stress for the majority of students, but more importantly, emotional intelligence had a significant correlation with this stress scale. As discussed previously, trait EI is better correlated with stress than ability EI. Individuals with high EI seem better in coping with stress and have better adaptive responses to come out of stressful situations. It follows that measuring trait EI can identify those individuals who are at risk of developing high stress if faced with acute stressful surroundings. Such individuals can then be trained for improving their emotional intelligence by way of a targeted approach. College administration, by identifying students at high risk of stress, can plan special counseling sessions to improve not only their academic performance, but their overall health and well-being in a holistic manner.

TABLE 6. CORRELATION BETWEEN EI PERCEIVED SCALE AND COVID STRESS

\begin{tabular}{|l|l|l|}
\hline $\begin{array}{l}\text { Correlation } \\
\text { coefficient }\end{array}$ & & \\
\hline & EI and Perceived & $-0.173(\mathrm{p}-$ \\
& stress & $0.069)^{*}$ \\
\hline & EI and Covid & $-0.208(\mathrm{p}-$ \\
& stress & $0.028)^{* *}$ \\
\hline
\end{tabular}

Note: $* P$ value $>0.05$

$* * \mathrm{P}$ value $<0.05$ 
A number of studies, both from India and abroad have looked on this aspect of Covid 19 stress and emotions generated by this situation. However, there are very few studies which have actually correlated EI with Covid induced stress. Most of the Indian studies have only assessed various emotions, but not emotional intelligence specifically. A few foreign studies have analysed Covid induced stress and made their own tools but they were either a slight modification of perceived stress scale or stress scale primarily related to the infection and health. These were published in early part of the pandemic and do not quite capture the Indian scenario in the later part where several issues affecting students like online classes, diminishing career opportunities and a difficult economic situation give rise to some unique stressful situations. A short stress questionnaire dealing with these issues was specifically designed for the purpose of this study which showed good internal reliability and correlated better with emotional intelligence than the perceived stress scale.

\section{A. Limitation and Future Direction}

There are some notable limitations of this study. First, it is based on single point observational correlation rather than experimental evidence, and hence cannot fully confirm its result. More longitudinal studies are required to determine how EI impacts on stress. But given the limited opportunity of this pandemic, a significant correlation between trait EI and acute stress gives an indirect proof to the concept and moreover, makes a strong point for identifying persons with low EI. Another limitation is a small sample size, especially regarding the role of gender and any conclusion about this needs larger studies. Similarly, the non-significant association with perceived stress may have been due to this limitation. However, as the adaptive responses to stress are complex and not uniform, a more generalized stress, as measured by PSS may not be solely dependent on EI, but rather on other related aspects of personality and intellect. Thus, it may be surmised from the above discussion that dealing with chronic generalized stress may require more than just emotional intelligence, but it may certainly play a role in dealing with acute stressful situations arising out of our external environment and moreover, its evaluation can help identify those individuals who are at risk of developing high stress if faced with such situation. For both college administrators and HR managers, this can be a framework for better targeted approach to improve academic performance, in case of students, or to improve productivity, in organizations. Future research could focus on finding the empirical evidence of an improved emotional intelligence working to help ameliorate the stress.

\section{CONCLUSION}

The main objective of the study was to assess the Emotional Intelligence (EI) of students in relation with Covid 19 stress and general stress as measured by two different scales. The outcome of this study showed a negative correlation between EI and Covid-19 stress, but there was no significant correlation with perceived stress. Our study shows that while EI may not be a good indicator of response to general chronic stress, it may prepare oneself better to deal with acute stressful situations like COVID-19. The study also shows that during unique stressful situations like Covid 19 pandemic, measures of stress should incorporate specific issues related to that situation to better understand the stress faced by population. We have used a tool to measure trait EI, which can be improved through training and it is hoped that the result of the present study can be applied in professional institutions for development of EI among students. For, it is not the intelligent, but emotionally intelligent individuals, who deal with stress in a better way.

\section{REFERENCES}

[1] Ciarrochi, J., Forgas, J. . R, \& Mayer, J. D. (Eds.). (2006). Emotional intelligence in everyday life (2nd ed.). Psychology Press/Erlbaum (UK) Taylor \& Francis.

[2] Petrides, K. V., Mikolajczak, M., Mavroveli, S., SanchezRuiz, M. J., Furnham, A., and Pérez-González, J. C. (2016). Developments in trait emotional intelligence research. Emotion Rev. 8, 335-341.

[3] Salovey, P., \& Mayer, J. D. (1990). Emotional intelligence. Imagination, Cognition, and Personality, 9, 185-211

[4] Mayer, J. D., \& Salovey, P. (1997). What is emotional intelligence? In P. Salovey \& D. Sluyter (Eds.), Emotional development and emotional intelligence: Implications for educators (pp. 3-31). New York, NY: Basic Books.

[5] Goleman, D. (1995). Emotional intelligence: Why it can matter more than IQ. New York, NY: Bantam Books.

[6] Goleman, D. (1998). Working with emotional intelligence. New York, NY: Bantam Books.

[7] Bar-On, R. (1997). Technical manual for the Emotional Quotient Inventory. Toronto, Ontario, Canada: MultiHealth Systems.

[8] Petrides KV, Pita R, Kokkinaki F.(2007) The location of trait emotional intelligence in personality factor space. $\mathrm{Br}$ J Psychol.98(2):273-89.doi:10.1348/000712606X120618.

[9] Petrides, K. V., and Furnham, A. (2000). On the dimensional structure of emotional intelligence. Personal. Indivi. Differ. 29, 313-320. doi: 10.1016/S01918869(99)00195-6

[10] Pérez, J. C., Petrides, K. V., and Furnham, A. (2005). Measuring Trait Emotional Intelligence In (Eds) R. Schulze and R. D. Roberts. Emotional intelligence: An International Handbook, Cambridge, MA: Hogrefe \& Huber. (pp 181-201).

[11] Martins, A., Ramalho, N. C., and Morin, E. M. (2010). A comprehensive meta analysis of the relationship between emotional intelligence and health. Pers.Individ. Dif. 49, 554-564. doi: 10.1016/j.paid.2010.05.029

[12] Panagi, L., Poole, L., Hackett, R. A., and Steptoe, A. (2018). Happiness and inflammatory responses to acute stress in people with Type 2 diabetes. Ann.Behav. Med. 53, 309-320. 
[13] Gilar-Corbi R, Pozo-Rico T, Sa'nchez B, Castejo'n JL (2019) Can emotional intelligence be improved? A randomized experimental study of a businessoriented EI training program for senior managers. PLoS ONE 14(10): e0224254. https:// doi.org/10.1371/journal.pone.0224254

[14] Nelis D., Kotsou I., Quoidbach J., Hansenne M., Weytens F., Dupuis P., et al. (2011) Increasing emotional competence improves psychological and physical well-being, social relationships, and employability. Emotion. ; 11(2), 354-366. https://doi.org/10.1037/a0021554

[15] Kotsou I., et al. (2018) Improving Emotional Intelligence:A Systematic Review of Existing Work and Future Challenges.Emotion Review, doi.org/10.1177/1754073917735902

[16] Mayer, J. D., Salovey, P., and Caruso, D. R. (2002). Mayer-Salovey-Caruso Emotional Intelligence Test (MSCEIT) User's Manual. Toronto, ON:MHS Publishers.

[17] Boyatzis, R. E., and Goleman, D. (2007). Emotional and Social Competency Inventory. Boston, MA: The Hay Group

[18] Schutte, N. S., Malouff, J. M., Hall, L. E., Haggerty, D. J., Cooper, J.T., Golden, C. J., et al. (1998). Development and validation of a measure of emotional intelligence. Personal. Indivi. Diff. 25, 167-177.

[19] Petrides, K. V., and Furnham, A. (2001). Trait emotional intelligence: psychometric investigation with reference to established trait taxonomies. Eur.J. Person. 15, 425-448. doi: 10.1002/per.416

[20] Malouff, John \& Bhullar, Navjot. (2009). The Assessing Emotions Scale. In C Stough, D Saklofske, $\mathrm{J}$ Parker (Eds): Assessing Emotional Intelligence (pp.119-134) US: Springer Publishing Editors: DOI: 10.1007/978-0-387-88370-0_7

[21] Van Rooy, D. L., Dilchert, S., Viswesvaran, C., \& Ones, D. S. (2006). Multiplying intelligences: Are general, emotional, and practical intelligences equal? In K. R. Murphy (Ed.), A critique of emotional intelligence (pp. 235-262). Mahwah, NJ: Erlbaum.

[22] Joseph, D. L., \& Newman, D. A. (2010). Emotional intelligence: An integrative meta-analysis and cascading model. Journal of Applied Psychology, 95, 54-78.

[23] Extremera, N., Fernández-Berrocal, P., \& Salovey, P. (2006). Spanish Version of the Mayer-SaloveyCaruso Emotional Intelligence Test (MSCEIT) Version 2.0: Reliabilities, Age, and Gender Differences. Psicothema, 18, 42-48.

[24] Koydemir, Selda \& Şimşek, Ömer \& Schuetz, Astrid \& Tipandjan, Arun. (2012). Differences in How Trait Emotional Intelligence Predicts Life Satisfaction: The Role of Affect Balance Versus Social Support in India and Germany. Journal of Happiness Studies. 14. 10.1007/s10902-011-9315-1.

[25] Petrides, K. V. and Furnham A. (2000). Gender Differences in Measured and Self-Estimated Trait
Emotional Intelligence. Sex Roles: A Journal of Research, 42 (5), 449-461.

[26] Fernández-Berrocal, Pablo \& Cabello, Rosario \& Castillo Gualda, Ruth \& Extremera, Natalio. (2012). Gender differences in emotional intelligence: The mediating effect of age. Behavioral Psychology/ Psicologia Conductual. 20. 77-89.

[27] Bar-On, R., Brown, J. M., Kirkcaldy, B., \& Thome, E. (2000). Emotional expression and implications for occupational stress; an application of the Emotional Quotient Inventory (EQ-i). Personality and Individual Differences, 28, 1107-1118.

[28] Brackett, M. A., Rivers, S. E., Shiffman, S., Lerner, N., \& Salovey, P. (2006). Relating emotional abilities to social functioning: A comparison of self-report and performance measures of emotional intelligence. Journal of Personality and Social Psychology, 91, 780-795. doi: 10.1037/0022-3514.91.4.780

[29] Brown, R. F., \& Schutte, N. S. (2006). Direct and indirect relationships between emotional intelligence and subjective fatigue in university students. Journal of Psychosomatic Research, 60, 585-593.

[30] Pooja P, Kumar P.(2016) Demographic Variables and Its Effect on Emotional Intelligence: A Study on Indian Service Sector Employees. Ann Neurosci. 23(1):18-24. doi: $10.1159 / 000443552$..

[31] Chandra, A., Gayatri, A., \& Devi, D. (2017). Assessment of emotional intelligence in first year medical graduatesA Questionnaire based study. International Journal of Physiology, 5, 124-126.

[32] Shanmugham R (2019), Gender differences in emotional quotient among professional students. International Journal of Medical Research \& Health Sciences, 8(7): 79

[33] Joshi, D., \& Dutta, I. (2014). Emotional intelligence among secondary students: Role of gender and type of school. MIER Journal of Educational Studies, Trends \& Practices, 4, 167-182

[34] Meshkat, M, Nejati, Reza. (2017). Does Emotional Intelligence Depend on Gender? A Study on Undergraduate English Majors of Three Iranian Universities. SAGE Open.7. doi:10.1177/2158244017725796

[35] Nasir, M., \& Masrur, R. (2010). An Exploration of Emotional Intelligence of the Students of IIUI in Relation to Gender, Age and Academic Achievement. Bulletin of Education and Research , 32,1, 37-51.

[36] Shanwal, Vinod \& Kaur, Gurpreet \& Singh, S.B. \& Kumar, Sudeep. (2006). Emotional Intelligence in School Children: A socio-demographic study. Journal of Psychosocial Research. 1. 1-13.

[37] Bindu, P \& Thomas, Immanuel. (2006). Gender Differences in Emotional Intelligence. Psychological Studies. 51. 261-268..

[38] Lazarus RS and Folkman S. (1984). Stress, Appraisal, and Coping, New York: 4. Springer

[39] Hunt N and Evans D. (2004). Predicting Traumatic Stress Using Emotional Intelligence. Behaviour Research and Therapy. 42: 791-798. 
[40] Matthews, G., Zeidner,M., and Roberts, R. (2017). Emotional intelligence, health, and stress, in C. L. Cooper and J. C. Quick (Eds) .The Handbook of Stress and Health: A Guide to Research and Practice. 312-326 eds Sussex: Wiley.

[41] Extremera, N., Durán, A., and Rey, L. (2007). Perceived emotional intelligence and dispositional optimism-pessimism: analyzing their role in predicting psychological adjustment among adolescents. Pers. Individ. Dif. 42, 1069-1079.

[42] Mikolajczak, M., Petrides, K. V., Coumans, N., and Luminet, O. (2009). The moderating effect of trait emotional intelligence on mood deterioration following laboratory-induced stress. Int. J. Clin. Health Psychol. 9, 455-477.

[43] Velten, E. (1968). A laboratory task for induction of mood states. Behav. Res. Ther.6, 473-482.

[44] Ramos, N., Fernández-Berrocal, P., and Extremera, N. (2007). Perceived emotional intelligence facilitates cognitive-emotional processes of adaptation to an acute stressor. Cogn. Emotion 21, 758-772.

[45] Kirschbaum, C., Pirke, K. M., and Hellhammer, D. H. (1993). The 'Trier Social Stress Test': a tool for investigating psychobiological stress responses in a laboratory setting. Neuropsychobiology 28, 76-81.

[46] Lane, A.M., Thelwell, R., and Devonport, T. J. (2009). Emotional intelligence and mood states associated with optimal performance. E J. Appl. Psychol. 5, 67-73.

[47] Denson, T. F., Spanovic, M., and Miller, N. (2009). Cognitive appraisals and emotions predict cortisol and immune responses: a meta-analysis of acute laboratory social stressors and emotion inductions. Psychol. Bull. 135, 823-853.

[48] Wu M, Xu W, Yao Y, Zhang L, Guo L, Fan J, Chen J.(2020) Mental health status of students' parents during COVID-19 pandemic and its influence factors. Gen Psychiatr. 21;33(4):e100250

[49] Dwivedi D, Kaur N, Shukla S, Gandhi A, Tripathi S. 2020; Perception of stress among medical undergraduate during coronavirus disease-19 pandemic on exposure to online teaching. Natl $\mathrm{J}$ Physiol Pharm Pharmacol. 10(8): 657-662. .

[50] Karthick,K . J. Vinodha Evangeline (2020) Covid 19: Unprecedented necessity of e-learning platform and emotional intelligence among students in higher education institutions in Tamilnadu., International Research Journal of Management Sociology \& Humanities ,Vol.11 5,s.1
[51] Rehman U, Shahnawaz MG, Khan NH, Kharshiing KD, Khursheed M, Gupta K, Kashyap D, Uniyal R. Depression,(2020)Anxiety and Stress Among Indians in Times of Covid-19 Lockdown. Community Mental Health J. 23:1-7.

[52] Prentice C, Zeidan S, Wang X. (2020) Personality, trait EI and coping with COVID 19 measures. Int J Disaster Risk Reduct.;51:101789.

[53] Moroń M, Biolik-Moroń M. (2020) Trait emotional intelligence and emotional experiences during the COVID-19 pandemic outbreak in Poland: A daily diary study. Pers Individ Dif. 1;168:110348. doi: 10.1016/j.paid.2020.110348. Epub 2020 Aug 20

[54] Pedrozo-pupo, Carlos J; Pedrozo-cortes, José M \& Campo-arias, A. (2020,) Perceived stress associated with COVID-19 epidemic in Colombia: an online survey. Cad. Saúde Pública [online]. .36, n.5 doi.org/10.1590/0102-311x00090520.

[55] Taylor, Steven \& Landry, Caeleigh \& Paluszek, Michelle \& Fergus, Thomas \& Mckay, Dean \& Asmundson, Gordon. (2020). Development and Initial Validation of the COVID Stress Scales. Journal of Anxiety Disorders. 72. 102232.

[56] Cohen, Sheldon, et al. 1983. A Global Measure of Perceived Stress. Journal of Health and Social Behavior, vol. 24, no. 4, pp. 385-396

\section{SuPPLEMENT. COVID-19 StRESS SCALE}

The following set of questions ask about the impact of COVID-19 and the stress related to it. Answer quickly with the alternative that seems most appropriate. The options are as follows.

Never, Almost never, Sometimes, Fairly often, Very often. (made on google forms as Likert scale)

1. Have you felt stressed about the impact of COVID-19 on your studies

2. Are you worried that online classes are not enough to fulfill your academic and learning needs

3. In the last month, how often have you felt nervous and anxious that the pandemic may affect your career options

4. Do you feel upset that the pandemic will have a longlasting impact on the economy and the job opportunities

5. How often have you feel confident that there are new opportunities for both learning and career because of pandemic

6. How often have you felt anger that the government strategies may not be enough to control the pandemic

7. How often have you felt worried that you or your family members may catch the virus

8. How often you felt worried that measures like wearing mask and social distancing will not be able to control the spread of the virus 